\title{
INVESTIGATION OF MOLECULAR INTERACTION OF AMINO ACIDS IN AQUEOUS n-PROPANOL SOLUTIONS AT 308.15 K
}

\author{
Richard D' Souza' ${ }^{1}$ G. Meenakshi ${ }^{2}$ \\ ${ }^{I}$ Research Scholar, Department of Physics, Bharathiyar University, Coimbatore, Tamil Nadu, India. \\ ${ }^{2}$ Associate Professor (Rtd), Department of Physics, Kanchimamunivar Center for PG Studies, Pondicherry, India
}

\begin{abstract}
The physical properties that has been investigated are, density $(\rho)$, viscosity $(\eta)$, and ultrasonic velocity $(U)$ of L-valine, L- leucine and L-glutamine in aqueous n-propanol solution (0\%-30\%) in steps of $10 \%$ at $308.15 \mathrm{~K}$ have been measured. The derived acoustical parameters namely adiabatic compressibility $(\beta)$, apparent molal compressibility $\left(\phi_{K}\right)$, apparent molal volume $\left(\phi_{V}\right)$, limiting apparent molal compressibility $\left(\phi_{K}^{\circ}\right)$, limiting apparent molal volume $\left(\phi_{V}^{\circ}\right)$ and their constants $\left(s_{k}, s_{v}\right)$, transfer adiabatic compressibility $\left(\Delta \phi^{\circ}{ }_{K}\right)$, transfer volume $\left(\Delta \phi^{\circ}{ }_{V}\right)$, and viscosity B-coefficient are calculated using the experimental data. The change that has been observed in the parameter with respect to molality of the solute has been interpreted in terms of ion-ion and ion- solvent interactions.
\end{abstract}

Key words: Molecular interaction, solute-solvent interaction, ion-ion interaction, ion-solvent interaction.

\section{INTRODUCTION}

In recent years, the Physicist wished to understand the structure of liquid molecules. The only means they had of investigating these structures were by chemical reaction that led to the changes which themselves were known. The liquids and liquid mixtures help chemical physicist to explore the "dynamic behavior" of rigid molecules, using both physical and chemical methods. Denaturation of globular proteins in aqueous solutions is a fundamental biological process which till date is not completely understood and continues to be a subject of extensive investigations [1]. Knowledge of various solute-solute and solute-solvent interactions is very important to understand various fundamental phenomena like stability of proteins, folding/unfolding processes, denaturation of proteins etc., in aqueous solutions [2]. It is rather difficult to study the interaction of protein molecules because it has got a nature of complex structure. It is quite interesting to study the physio- chemical behavior of the non-electrolyte like propanol with amino acids [3].

The physical properties of dilute aqueous solutions of nonelectrolytes depend on the solute and solvent i.e., water whose structure acts as breaker or maker. The influence of small quantity of amino acids over the hydrogen bonded structure of water in the solution may expect to yield good results. It will also help to study the nature of molecular interactions between the organic solute with water which act as a solvent [4].

\section{MATERIALS AND METHODS}

In the present study, the spectroscopic reagent (SR) and analytical reagent (AR) grades of minimum assay of $99.9 \%$ are used and obtained from E-Merck, Germany and Sd Fine chemicals, India. Water used in the experiment was deionized, distilled and are degassed to making solutions. An aqueous solution of n-propanol $0 \%-30 \% \mathrm{~mol} . \mathrm{dm}^{-3}$ in steps of $10 \%$ is prepared by volume and has been used for the present study. The amino acids in the concentration range of $0.02-0.1 \mathrm{~mol} \mathrm{dm}^{-3}$ has been made by volume on the molality concentration with a precision of $\pm 1 \times 10^{-4} \mathrm{~g}$ on an electronic digital balance (Model: Shimadzu Ax - 200). The density has been measured by using the relative measurement method with an accuracy of $\pm 0.01 \mathrm{~kg} \mathrm{~m}^{-3}$, and obtained by using a specific gravity bottle. An Ostwald's viscometer $(5 \mathrm{ml})$ has been used for the viscosity measurements. Efflux time has been determined using a digital chronometer within $\pm 0.01 \mathrm{~s}$. For velocity measurements, Ultrasonic interferometer having a frequency of $3 \mathrm{MHz}$ (Mittal Enterprises, New Delhi, Model: F-18) with an overall accuracy of $0.1 \%$ has been used. A digital electronic constant temperature bath has been used for experimental purpose. The accuracy of the temperature measurement is $\pm 0.1 \mathrm{~K}$.

\section{RESULT AND DISCUSSION}

The values of ultrasonic velocity (U), density ( $\rho)$, and viscosity $(\eta)$, for different molar concentrations of $L$ - valine, L-leucine and L-glutamine in aqueous n-propanol (0\% $30 \%) \mathrm{M}$ solution at $308.15 \mathrm{~K}$ is reported in Table1. The values of adiabatic compressibility $(\beta)$, apparent molal compressibility $\left(\phi_{\mathrm{k}}\right)$, apparent molal volume $\left(\phi_{\mathrm{v}}\right)$, limiting apparent molal compressibility $\left(\phi^{\circ}\right)$, limiting apparent molal volume $\left(\phi^{\circ}{ }_{\mathrm{v}}\right)$ their constants $\left(\mathrm{S}_{\mathrm{k}}, \mathrm{S}_{\mathrm{v}}\right)$, are reported in Table 2, 3. The volumetric, compressibility and transport parameter have been calculated using the standard relations,

Adiabatic compressibility

$$
\beta=\frac{1}{U^{2} p}
$$


The apparent molar compressibility

$$
\varphi_{\mathrm{k}}=\frac{1000}{\mathrm{M}_{\mathrm{p}_{0}}}\left(\rho_{\mathrm{o}} \beta-\mathrm{p} \beta \mathrm{\beta o}\right)+\left(\frac{\beta_{0} \mathrm{M}_{\mathrm{w}}}{\mathrm{P}_{\mathrm{o}}}\right)
$$

(2)

where, $\mathrm{M}$ is the molal concentration of the solute and $\mathrm{M}_{\mathrm{w}}$ the molecular weight of the solute. $\varphi_{\mathrm{k}}$ is the function of $\mathrm{M}$ as obtained by Gucker (1993) [5] from Debye Huckel [6] and is given by

(3)

$$
\varphi_{\mathrm{k}}=\varphi_{\mathrm{k}}^{\mathrm{o}}+\mathrm{S}_{\mathrm{k}} \mathrm{M}^{1 / 2}
$$

where, $\varphi_{\mathrm{k}}^{\mathrm{o}}$ is the limiting apparent molar compressibility and $\mathrm{S}_{\mathrm{k}}$ is a constant.

The apparent molar volume $\varphi_{\mathrm{v}}$

$$
\varphi_{v}=\left(\frac{\mathrm{M}_{\mathrm{W}}}{\mathrm{p}}\right)-\left(\frac{1000\left(\mathrm{p}-\mathrm{p}_{0}\right.}{\mathrm{Mpp}_{\mathrm{p}}}\right)
$$

The apparent molar volume $\varphi_{\mathrm{v}}$ in according to empirical relation as:

(5)

$$
\varphi_{\mathrm{v}}=\varphi^{\mathrm{o}}{ }_{\mathrm{v}}+\mathrm{S}_{\mathrm{v}} \mathrm{M}^{1 / 2}
$$

\begin{tabular}{|c|c|c|c|c|c|c|c|c|c|c|c|c|}
\hline \multirow{3}{*}{$\begin{array}{c}\text { M } \\
\left(\text { mol.dm }^{-3}\right)\end{array}$} & \multicolumn{4}{|c|}{$\rho /\left(\right.$ kg.m $\left.\mathbf{m}^{-3}\right)$} & \multicolumn{4}{|c|}{$\eta /\left(\times 10^{-3} \mathrm{Nsm}^{-2}\right)$} & \multicolumn{4}{|c|}{$\mathrm{U} /\left(\mathrm{x}^{\mathrm{N0}} \mathrm{-}^{-10} \mathrm{~m} \cdot \mathrm{s}^{-1}\right)$} \\
\hline & \multicolumn{12}{|c|}{ Water + n-Propanol + L-valine } \\
\hline & $\mathbf{0 \%}$ & $10 \%$ & $20 \%$ & $30 \%$ & $\mathbf{0 \%}$ & $10 \%$ & $20 \%$ & $30 \%$ & 0\% & $10 \%$ & $20 \%$ & $30 \%$ \\
\hline 0.00 & 994.0 & 980.1 & 966.2 & 952.9 & 0.7190 & 0.9614 & 1.0576 & 1.2861 & 1519.5 & 1537.6 & 1555.2 & 1575.7 \\
\hline 0.02 & 994.7 & 981.0 & 967.3 & 954.2 & 0.8060 & 0.9926 & 1.0760 & 1.3062 & 1520.6 & 1540.2 & 1558.0 & 1579.2 \\
\hline 0.04 & 995.5 & 982.2 & 968.8 & 955.2 & 0.8296 & 1.0001 & 1.0870 & 1.3322 & 1524.7 & 1542.6 & 1560.5 & 1584.2 \\
\hline 0.06 & 996.5 & 983.6 & 970.4 & 957.2 & 0.8578 & 1.0128 & 1.1005 & 1.3516 & 1527.4 & 1545.0 & 1562.8 & 1586.2 \\
\hline 0.08 & 997.8 & 985.1 & 971.9 & 959.0 & 0.8827 & 1.0255 & 1.1251 & 1.3878 & 1530.8 & 1547.8 & 1565.3 & 1590.3 \\
\hline 0.10 & 999.2 & 986.8 & 973.6 & 960.8 & 0.9113 & 1.0360 & 1.1595 & 1.4044 & 1535.2 & 1552.3 & 1570.1 & 1594.2 \\
\hline \multicolumn{13}{|c|}{ Water + n-Propanol + L-Leucine } \\
\hline 0.00 & 994.0 & 980.1 & 966.2 & 952.9 & 0.7190 & 0.9614 & 1.0576 & 1.2861 & 1519.5 & 1537.6 & 1555.2 & 1575.7 \\
\hline 0.02 & 996.7 & 983.4 & 971.0 & 958.7 & 0.7943 & 0.9711 & 1.1208 & 1.3292 & 1523.9 & 1540.9 & 1559.6 & 1579.1 \\
\hline 0.04 & 998.2 & 985.4 & 973.0 & 960.6 & 0.8046 & $0.99 \mathrm{~s} 45$ & 1.1372 & 1.3713 & 1526.6 & 1543.7 & 1562.2 & 1585.3 \\
\hline 0.06 & 999.9 & 987.0 & 974.8 & 962.6 & 0.8122 & 1.0050 & 1.1530 & 1.3873 & 1529.1 & 1546.7 & 1565.0 & 1588.9 \\
\hline 0.08 & 1001.6 & 989.2 & 976.8 & 964.4 & 0.8301 & 1.0274 & 1.1705 & 1.4059 & 1530.8 & 1549.7 & 1567.6 & 1593.2 \\
\hline 0.10 & 1002.9 & 990.6 & 978.3 & 966.0 & 0.8360 & 1.0581 & 1.1839 & 1.4440 & 1533.9 & 1552.4 & 1570.9 & 1594.5 \\
\hline \multicolumn{13}{|c|}{ Water + n-Propanol + L-Glutamine } \\
\hline 0.00 & 994.0 & 980.1 & 966.2 & 952.9 & 0.7190 & 0.9614 & 1.0576 & 1.2861 & 1519.5 & 1537.6 & 1555.2 & 1575.7 \\
\hline 0.02 & 997.2 & 984.6 & 972.0 & 959.4 & 0.7996 & 0.9711 & 1.2765 & 1.5215 & 1523.5 & 1542.3 & 1559.9 & 1579.8 \\
\hline 0.04 & 998.3 & 985.8 & 973.3 & 960.8 & 0.8061 & 0.9842 & 1.3012 & 1.5423 & 1526.3 & 1545.0 & 1563.7 & 1586.2 \\
\hline 0.06 & 1000.3 & 987.6 & 975.4 & 963.2 & 0.8161 & 1.0006 & 1.3068 & 1.5623 & 1529.6 & 1548.3 & 1567.0 & 1589.4 \\
\hline 0.08 & 1002.2 & 990.0 & 977.8 & 965.6 & 0.8343 & 1.0156 & 1.3197 & 1.5754 & 1532.3 & 1551.9 & 1570.4 & 1592.2 \\
\hline 0.10 & 1003.1 & 991.3 & 979.5 & 967.7 & 0.8537 & 1.0289 & 1.3397 & 1.5948 & 1535.2 & 1554.3 & 1573.4 & 1594.3 \\
\hline
\end{tabular}

Table - 1: Density $(\rho)$, viscosity $(\eta)$ and ultrasonic velocity $(U)$ of the amino acids in aqueous solutions of n-propanol at $308.15 \mathrm{~K}$ 
The density ( $\rho)$ increases with increase of molal concentration of amino acids and decreases with increase of concentration of n-propanol (Table 1), the values of ultrasonic velocity increase with increase in molal concentration of amino acids and also with n-propanol content. The observed results suggest a moderate strong electrolytic nature in which the solutes tend to attract the solvent molecules in the aqueous solution.

When amino acids are dissolved the water structure is disturbed initially, followed by a structural reorganization leaving the molecules in closely fitting helical cavities [8]. This will increase the density structure of water. Hence the density of medium is affected. The increase in the ultrasonic velocity may be attributed to the cohesion brought about by the hydration. When the amino acids are dissolved in aqueous alcohol, the cations $\mathrm{NH}_{3}{ }^{+}$and anions $\mathrm{COO}^{-}$are formed. The water molecules are attached to the ions strongly by the electrostatic forces which introduce a greater cohesion in the solution. The cohesion effect of medium generally increases with the increase of amino acid concentration. The increased associations observed in these solutions, may also be due to water structure enhancement brought by the increase of electrostriction in the presence of n-propanol.
The adiabatic compressibility $(\beta)$ (Table-2) decreases with increase in the concentration of amino acids and also with the n-propanol content.

The decrease in adiabatic compressibility is attributed to the influence of the electrostatic field of ions $\left(\mathrm{NH}_{3}{ }^{+}\right.$and $\left.\mathrm{COO}^{-}\right)$on the surrounding solvent molecules $\left(\mathrm{C}_{3} \mathrm{H}_{7}^{+}, \mathrm{OH}^{-}\right)$.

The other observed results are on $\left(\phi_{\mathrm{k}}\right)$ and $\left(\phi_{\mathrm{v}}\right)$ (Table 2$)$ of L-valine, L-leucine and L-glutamine in aqueous n-propanol solutions at $308.15 \mathrm{~K}$ has been summarized as follows.

(i) All $\left(\phi_{\mathrm{k}}\right)$ and $\left(\phi_{\mathrm{v}}\right)$ values are negative over the entire system.

(ii) With increase in concentration of amino acids as well as n-propanol in system-I the values of $\left(\phi_{\mathrm{k}}\right)$ and $\left(\phi_{\mathrm{v}}\right)$ decreases. For system II and II the values of $\left(\phi_{\mathrm{k}}\right)$ and $\left(\phi_{\mathrm{v}}\right)$ increases with increase in concentration of amino acid but decreases with the increase in concentration of n-propanol.

(iii) For $\left(\phi_{\mathrm{k}}\right)$ and $\left(\phi_{\mathrm{v}}\right)$ values the magnitude are in the order L-valine > L-leucine > L-glutamine.

Table - 2 : Values of adiabatic compressibility ( $\beta$ ), apparent molar compressibility ( $\left.\varphi_{\mathrm{k}}\right)$ and apparent molar volume $\left(\varphi_{\mathrm{v}}\right)$ of amino acids in aqueous n-propanol solutions at $308.15 \mathrm{~K}$.

\begin{tabular}{|c|c|c|c|c|c|c|c|c|c|c|c|c|}
\hline \multirow{2}{*}{$\begin{array}{c}\mathrm{M} \\
(\mathrm{mol} . \\
\left.\mathbf{d m}^{-3}\right)\end{array}$} & \multicolumn{4}{|c|}{$\beta /\left(\times 10^{-10} \mathrm{~m}^{2} \mathrm{~N}^{-1}\right)$} & \multicolumn{4}{|c|}{$-\varphi_{\mathrm{k}} /\left(\mathrm{x} 10^{-7} \mathrm{~m}^{2} \mathrm{~N}^{-1}\right)$} & \multicolumn{4}{|c|}{$-\varphi_{\mathrm{v}} /\left(\mathrm{x} \mathrm{10}^{-3} \mathrm{~m}^{3} \mathrm{~mol}^{-1}\right)$} \\
\hline & $0 \%$ & $10 \%$ & $20 \%$ & $30 \%$ & $0 \%$ & $10 \%$ & $20 \%$ & $30 \%$ & $0 \%$ & $10 \%$ & $20 \%$ & $30 \%$ \\
\hline \multicolumn{13}{|c|}{ System - I } \\
\hline 0.00 & 4.3572 & 4.3156 & 4.2791 & 4.2267 & -- & -- & -- & & -- & -- & -- & \\
\hline 0.02 & 4.3474 & 4.3012 & 4.2589 & 4.2023 & 0.6653 & 0.9621 & 1.2535 & 1.3546 & 35.28 & 46.68 & 58.72 & 71.36 \\
\hline 0.04 & 4.3206 & 4.2785 & 4.2387 & 4.1714 & 1.0903 & 1.1586 & 1.2978 & 1.5266 & 37.78 & 54.41 & 69.31 & 76.74 \\
\hline 0.06 & 4.3013 & 4.2591 & 4.2193 & 4.1522 & 1.1362 & 1.1985 & 1.3066 & 1.6006 & 41.95 & 60.39 & 71.53 & 78.44 \\
\hline 0.08 & 4.2766 & 4.2369 & 4.1993 & 4.1226 & 1.2102 & 1.2424 & 1.3130 & 1.6394 & 47.78 & 64.61 & 75.75 & 83.31 \\
\hline 0.10 & 4.2461 & 4.2050 & 4.1660 & 4.0950 & 1.2293 & 1.3570 & 1.4321 & 1.6407 & 52.23 & 69.15 & 78.55 & 86.16 \\
\hline \multicolumn{13}{|c|}{ System - II } \\
\hline 0.00 & 4.3572 & 4.3156 & 4.2791 & 4.2267 & -- & -- & -- & & -- & -- & -- & \\
\hline 0.02 & 4.3203 & 4.2827 & 4.2340 & 4.1828 & 2.0595 & 2.3715 & 3.3179 & 3.4813 & 136.13 & 171.05 & 255.67 & 317.30 \\
\hline 0.04 & 4.2986 & 4.2585 & 4.2112 & 4.1422 & 1.9252 & 2.0109 & 2.4503 & 2.9665 & 105.69 & 131.06 & 180.69 & 210.16 \\
\hline 0.06 & 4.2773 & 4.2351 & 4.1884 & 4.1148 & 1.7627 & 1.8480 & 2.1464 & 2.5820 & 98.80 & 118.74 & 152.04 & 176.11 \\
\hline 0.08 & 4.2601 & 4.2094 & 4.1660 & 4.0850 & 1.6301 & 1.8283 & 2.0005 & 2.4088 & 95.28 & 117.19 & 140.25 & 156.28 \\
\hline 0.10 & 4.2378 & 4.1888 & 4.1421 & 4.0712 & 1.5841 & 1.7303 & 1.9058 & 2.1360 & 89.14 & 108.01 & 127.87 & 142.17 \\
\hline \multicolumn{13}{|c|}{ System - III } \\
\hline 0.00 & 4.3572 & 4.3156 & 4.2791 & 4.2267 & -- & -- & -- & & -- & -- & -- & \\
\hline 0.02 & 4.3204 & 4.2697 & 4.2280 & 4.1763 & 2.4513 & 3.2857 & 3.5430 & 3.9615 & 161.27 & 233.01 & 308.64 & 355.34 \\
\hline 0.04 & 4.2999 & 4.2496 & 4.2019 & 4.1365 & 1.9037 & 2.2774 & 2.7161 & 3.1310 & 108.18 & 147.33 & 188.57 & 215.56 \\
\hline 0.06 & 4.2761 & 4.2238 & 4.1752 & 4.1102 & 1.8119 & 2.0804 & 2.4107 & 2.7031 & 105.45 & 128.99 & 162.54 & 186.88 \\
\hline 0.08 & 4.2493 & 4.1940 & 4.1469 & 4.0850 & 1.7980 & 2.0648 & 2.2946 & 2.4754 & 102.74 & 127.39 & 153.33 & 172.38 \\
\hline 0.10 & 4.2298 & 4.1756 & 4.1239 & 4.0652 & 1.6728 & 1.8931 & 2.1410 & 2.2714 & 91.12 & 115.12 & 140.38 & 160.34 \\
\hline
\end{tabular}


The negative values of $\left(\phi_{\mathrm{k}}\right)$ and $\left(\phi_{\mathrm{v}}\right)$ indicates ionic and hydrophilic interactions occurring in these systems [10]. The magnitude of $\left(\phi_{\mathrm{k}}\right)$ strongly supports our earlier view of the ultrasonic velocity and adiabatic compressibility. The negative values of $\left(\phi_{\mathrm{v}}\right)$ indicate electrostrictive solvation of ions [11]. The value of $(\phi v)$ shows that stronger molecular association has been found in L-valine.

Hence L-valine is a more effective structure maker than other two amino acids.

From Table 3 , the changes observed in $\left(\phi^{\circ}{ }_{k}\right)$ and $\left(S_{k}\right)$ values with increase of amino acids concentration may be due to ion-solvent interaction and ion-ion interactions in the solution. The values of $\left(\phi^{\circ}{ }_{k}\right)$ are negative and it decreases with increasing concentration of $n$-propanol in all the systems studied. It confirms the existence of ion-solvent interaction in the mixtures.

The magnitude of $\left(\phi_{\mathrm{k}}^{\circ}\right)$ is in the order L-valine > L-leucine $>$ L-glutamine. The values of $\left(S_{k}\right)$ is negative for L-valine (Table 3), but it is positive for other two amino acids. The negative values of $\left(S_{k}\right)$ Indicate weakening of ion-ion interaction and suggest the structure breaking effect of the amino acids.

It is well known that solutes causing electrostriction lead to decrease in compressibility of the solution. This is reflected by the negative values of the $\left(\phi_{\mathrm{k}}\right)$ values of amino acids.

The volume behavior of the solute at infinite dilution is satisfactorily represented by $\left(\phi^{\circ}\right)$, which is independent of

the ion-ion interactions and provides information concerning ion-solvent interactions. Table 3 reveals that the values of $\left(\phi_{\mathrm{v}}^{\circ}\right)$ are negative in all the three amino acids. From table 3, $\left(S_{v}\right)$ values are negative for L-valine and positive for the other two amino acids. The negative $\left(\mathrm{S}_{\mathrm{v}}\right)$ values for $\mathrm{L}$-valine suggest the presence of weak ion-ion interactions [12]. Therefore it causes the complex ion formation in the systems. The values of transfer adiabatic compressibility $\left(\Delta \phi_{\mathrm{k}}^{\circ}\right)$ and transfer volume $\left(\Delta \phi_{\mathrm{v}}^{\circ}\right)$ (Table 3$)$ are negative and it decreases with increasing concentration of n-propanol in all the three amino acid systems. It suggests that the existence of ion-solvent interaction in the mixtures.

Table - 3 Values of limiting apparent molal compressibility $\left(\varphi_{\mathrm{k}}^{\mathrm{a}}\right)$, limiting apparent molal volume ( $\left.\varphi_{\mathrm{v}}^{\mathrm{z}}\right)$, their constants

$S_{k}$ and $S_{v}$, transfer adiabatic compressibility $\left(\Delta \varphi_{\mathrm{k}}^{\mathrm{a}}\right)$ and transfer volume $\left(\Delta \varphi_{\mathrm{V}}^{\mathrm{a}}\right)$ of the amino acids in aqueous n-propanol solutions at $308.15 \mathrm{~K}$

\begin{tabular}{|c|c|c|c|c|c|c|c|c|c|}
\hline $\begin{array}{l}\text { Amino } \\
\text { Acid }\end{array}$ & $\begin{array}{c}\mathrm{M} / \\
\left(\mathrm{mol} . \mathrm{Kg}^{-1}\right)\end{array}$ & $\begin{array}{c}-\varphi_{\mathrm{k}}^{2} / \\
\left(\times 10^{-7}\right. \\
\left.\mathbf{m}^{2} \mathbf{N}^{-1}\right) \\
\end{array}$ & $\begin{array}{c}-\varphi_{V}^{a} / \\
\left(\times \mathbf{1 0}^{-3} \mathbf{m}^{3}\right. \\
\left.\mathbf{m o l}^{-1}\right)\end{array}$ & $\begin{array}{c}\mathrm{S}_{\mathrm{k}} / \\
\left(\times \mathbf{1 0}^{-7} \mathrm{~N}^{-1}\right. \\
\left.\mathbf{m}^{-1} \mathbf{m o l}^{-1}\right)\end{array}$ & $\begin{array}{c}\mathrm{S}_{\mathrm{v}} /\left(\times \mathbf{1 0}^{-3}\right. \\
\mathrm{m}^{3} \mathbf{L}^{\mathbf{1} / 2} \\
\left.\mathrm{~mol}^{-3 / 2}\right)\end{array}$ & $\begin{array}{c}\Delta \varphi_{\mathrm{k}}^{2} \\
/\left(\times 10^{-7}\right. \\
\left.\mathbf{m}^{2} \mathbf{N}^{-1}\right)\end{array}$ & $\begin{array}{c}\Delta \varphi_{V}^{a} \\
/\left(\times 10^{-3}\right. \\
\left.\mathbf{m}^{3} \mathbf{m o l}^{-1}\right) \\
\end{array}$ & $\begin{array}{c}\mathrm{A} / \\
\left(\mathrm{dm}^{3 / 2}\right. \\
\left.\mathrm{mol}^{-1 / 2}\right)\end{array}$ & $\begin{array}{c}\mathrm{B} /\left(\mathrm{dm}^{3 / 2}\right. \\
\left.\mathrm{mol}^{-1}\right)\end{array}$ \\
\hline \multirow{4}{*}{ 苞 } & $0 \%$ & 0.3522 & 20.46 & -3.0117 & -95.06 & - & - & 0.8210 & -0.0349 \\
\hline & $10 \%$ & 0.7044 & 29.11 & -2.0216 & -126.25 & -0.3522 & -8.65 & 0.1982 & 0.1168 \\
\hline & $20 \%$ & 1.1286 & 45.41 & -0.8096 & -106.97 & -0.7764 & -24.95 & -0.0384 & 0.9700 \\
\hline & $30 \%$ & 1.1663 & 59.85 & -1.6285 & -81.62 & -0.8141 & -39.39 & -0.0357 & 1.0517 \\
\hline \multirow{4}{*}{ } & $0 \%$ & 2.4107 & 164.68 & 2.6080 & 251.72 & - & - & 0.8746 & -1.2209 \\
\hline & $10 \%$ & 2.7867 & 209.04 & 3.4966 & 336.75 & -0.376 & -44.36 & -0.1051 & 1.2781 \\
\hline & $20 \%$ & 4.2240 & 338.96 & 7.8453 & 707.24 & -1.8133 & -174.28 & 0.4427 & -0.2459 \\
\hline & $30 \%$ & 4.5015 & 429.68 & 7.5367 & 969.18 & -2.0908 & -265.00 & -0.1546 & 0.6913 \\
\hline \multirow{4}{*}{ 䍘 } & $0 \%$ & 3.0022 & 197.5 & 4.4574 & 0.3534 & - & - & 0.8882 & -1.1238 \\
\hline & $10 \%$ & 4.0460 & 297.7 & 7.2800 & 0.6226 & -1.0438 & -0.1002 & -0.0500 & 0.8670 \\
\hline & $20 \%$ & 4.4470 & 404.3 & 7.7035 & 0.9013 & -1.4448 & -0.2068 & 1.9129 & -3.6004 \\
\hline & $30 \%$ & 5.1630 & 467.1 & 9.5105 & 1.0505 & -2.1608 & -0.2696 & 1.6619 & -3.0269 \\
\hline
\end{tabular}

(1) Ion-hydrophilic interactions occurring between

In the case of amino acids $+\mathrm{n}$-propanol + water, when the solute-cosolute molecules come close enough, their cospheres overlaps and the following types of interactions are possible: zwitterionic centers of amino acids and the $-\mathrm{OH}$ group of n-propanol,

(2) Hydrophobic - hydrophilic interactions between nonpolar parts of amino acids or n-propanol and $-\mathrm{OH}$ group of n-propanol or zwitterionic centers of amino acids, and 
(3) hydrophobic-hydrophobic interactions occurring between the nonpolar parts of amino acids and the nonpolar parts of n-propanol.

Anwar Ali [13] was also suggested the similar types of interactions in the study of some amino acids with salts in aqueous medium.

On the basis of co-sphere overlap model [14] the $\left(\Delta \phi_{\mathrm{v}}^{\circ}\right)$ values can also be explained in terms of solute-cosolute (ion-ion) interactions. According to this model, ion-ion group interactions contribute positively whereas ion-nonpolar and non-polar-non-polar interactions contribute negatively to the $\left(\Delta \phi^{\circ}{ }_{\mathrm{v}}\right)$ values.

Therefore the negative values of $\left(\Delta \phi^{\circ}{ }_{\mathrm{k}}\right)$ and $\left(\Delta \phi^{\circ}{ }_{\mathrm{v}}\right)$ observed in all the three amino acids showed that the interaction contribution of type (ii) is stronger than that of type (i).

The study of Viscosity ( $\eta$ ), helps to understand the structure as well as molecular interactions occurring in the solutions. It is observed that the values of viscosity increases with increasing in solute concentration. This increasing effect indicates the existence of ion-solvent interaction occurring in these systems (Table 1).

Further to confirm the effect, the role of viscosity (B) coefficient has been obtained from Jones-Dole equations [15]. The (A) coefficient is negative and (B) coefficient is positive for L-valine whereas a reverse trend is observed for the other two amino acids (Table 3). Since there is a weak ion-ion interaction is occurred in L-valine, because (A) is a measure of ionic interaction, which is indicated by the negative and smaller magnitude of (A) values [16] for Lvaline and vice-versa for the other two amino acids.

The viscosity (B) coefficient [17] gives the effect of ion-solvent interactions on the solution viscosity. The positive (B) values suggest the presence of strong ionsolvent interactions vice-versa. The magnitude of $(\mathrm{B})$ is in the order L-valine > L-leucine > L-glutamine. The larger value of (B) shows structure making capacity of the solute.

\section{CONCLUSION}

In summary, from the magnitudes of $\beta, \phi_{\mathrm{k}}, \phi_{\mathrm{v}}$ and viscosity $\mathrm{B}$ coefficient, it can be concluded that L-valine in aqueous n-propanol solution possesses the strong ionsolvent interaction than the other two amino acids. The transfer volume $\left(\Delta \phi_{\mathrm{v}}^{\circ}\right)$ suggests an ionic hydrophobic group interaction which predominates over the ionic hydrophilic interactions and hydrophobic - hydrophobic interactions. From the co-sphere overlap model it can be concluded that ionic-hydrophobic interactions are dominating over the ionion and hydrophobic - hydrophilic interactions.

\section{REFERENCES}

[1]. Hedwig G.R., HoilandH., J. Chem. Thermodyn., 23 (1999), 1029.

[2]. Lin Q., HuX., Lin L., SangW., LiS., J. Chem. Eng. Data, 46522 (2001).

[3]. Hackel M., HinzH., HeduringG. R., J. Mol. Bio. 66 429 (1999).

[4]. Kumar P., Kumar S., SinghS., GangwarR. S., Oriental J. of Chem. 2011. 27 No:2, $639-644$.

[5]. Gucker, F.T., Chem.Rev., 13 (1993) 111

[6]. Debye, P., and Huckel, E., Z.Phys., 24 (1923) 305

[7]. Jones, A., and Dole, M., J.Am.Chem. Soc.,51(1929) 2950

[8]. Falkenhagen, H., and Vernon, E.L., Z.Phys., 33 (1932) 140

[9]. Kavanou J., water and solute water interactions (Holden-Day Amsterdam) (1964).

[10]. Sandu J.S\& Gurbis singh, J Ind. Chem. Soc., 65, 135 (1992).

[11]. Dhanalakshmi \& Jasmin E, J. Pure. Appl. Ultrasonics., 21, 79 (1999).

[12]. Biswajit Sinha, Bipulkumar Sarkar and Mahendranath Roy. J. Chem. Thermodyn., 40, 394 (2008).

[13]. Anwar Ali, Shahla Khan, Soghra Hyder \& Mohd Tariq, J. Chem. Thermodyn, 39, 613 (2007).

[14]. Gurney R.W., Ionic process in solution chapter-I (McGraw - Hill, New York) 1953.

[15]. Jones G., Dole M., J. Am. Chem. Soc., 51, 2950 (1929).

[16]. Man Singh, Maneesha Pandey, Rajeshkumar Yadav., Verma H.S., J. Mol. Liq., 135. 188 (2007).

[17]. Millero F. J., LosurdoA., ShinC., J. Phys. Chem., 82,784 (1978). 